\title{
Update on taxane development: new analogs and new formulations
}

This article was published in the following Dove Press journal:

Drug Design, Development and Therapy

10 December 2012

Number of times this article has been viewed

\author{
Jean A Yared \\ Katherine HR Tkaczuk \\ University of Maryland School \\ of Medicine, Marlene and Stewart \\ Greenebaum Cancer Center, \\ Baltimore, MD, USA
}

Correspondence: Katherine HR Tkaczuk University of Maryland School of Medicine, Marlene and Stewart Greenebaum Cancer Center, 22 South Greene Street, Baltimore, MD 2I 20I, USA

Tel +l 4I0 3287394

Fax + I 4103286896

Email ktkaczuk@umm.edu
Abstract: The taxanes (paclitaxel and docetaxel) represent an important class of antineoplastic agents that interfere with microtubule function leading to altered mitosis and cellular death. Paclitaxel $\left(\right.$ Taxol $\left.^{\circledR}\right)$ was originally extracted from a yew tree (Taxus spp., Taxaceae) a small slow-growing evergreen, coniferous tree. Due to the initial scarcity of paclitaxel, docetaxel $\left(\right.$ Taxotere $\left.^{\circledR}\right)$ a semisynthetic analog of paclitaxel produced from the needles of European yew tree, Taxus baccata was developed. Docetaxel differs from paclitaxel in two positions in its chemical structure and this small alteration makes it more water soluble. Today, paclitaxel and docetaxel are widely prescribed antineoplastic agents for a broad range of malignancies including lung cancer, breast cancer, prostate cancer, Kaposi's sarcoma, squamous cell carcinoma of the head and neck, gastric cancer, esophageal cancer, bladder cancer, and other carcinomas. Although very active clinically, paclitaxel and docetaxel have several clinical problems including poor drug solubility, serious dose-limiting toxicities such as myelosuppression, peripheral sensory neuropathy, allergic reactions, and eventual development of drug resistance. A number of these side effects have been associated with the solvents used for dilution of these antineoplastic agents: Cremophor EL for paclitaxel and polysorbate 80 for docetaxel. In addition, reports have linked these solvents to the alterations in paclitaxel and docetaxel pharmacokinetic profiles. In this review, we provide preclinical and clinical data on several novel taxanes formulations and analogs which are currently US Food and Drug Administration (FDA)-approved or in clinical development in various solid tumor malignancies. Of the new taxanes nab-paclitaxel and cabazitaxel have enjoyed clinical success and are FDA-approved; while many of the other compounds described in this review are unlikely to be further developed for clinical use in daily practice. Furthermore, the successful clinical emergence of novel nontaxane microtubuletargeting chemotherapy agents such as epothilones and eribulin is liable to further restrict the development of novel taxanes.

Keywords: taxane(s), novel taxanes, taxane analogs, new taxane formulations, new antimicrotubule agents

\section{Introduction}

The taxanes (paclitaxel and docetaxel) represent a novel class of antineoplastic agents that interfere with microtubule function leading to altered mitosis and cellular death. Paclitaxel was originally extracted from a yew tree (Taxus spp., Taxaceae), a small slow-growing evergreen, coniferous tree. In the early 1950s, the US National Cancer Institute (NCI) started a screening program of cytotoxic plant extracts. In 1966, Wani and Wall isolated paclitaxel from Taxus brevifolia. ${ }^{1}$ Bristol-Myers Squibb (New York, NY) eventually developed Cremophor EL (CrEL), an ethanol formulation of paclitaxel, 
and commercialized it widely for treatment of solid tumor malignancies. Due to the initial scarcity of paclitaxel, (Sanofi France) developed docetaxel (Taxotere ${ }^{\circledR}$ ) a semisynthetic analog of paclitaxel produced from the needles of European yew tree, Taxus baccata. Docetaxel differs from paclitaxel at two positions in its chemical structure and this small alteration makes it more water soluble. Today, paclitaxel and docetaxel are widely prescribed antineoplastic agents for a broad range of malignancies including lung cancer, breast cancer, prostate cancer, Kaposi's sarcoma, squamous cell carcinoma of the head and neck, gastric cancer, esophageal cancer, bladder cancer, and other carcinomas. Although very active clinically, paclitaxel and docetaxel are associated with many serious side effects which often preclude continued use of these agents in patients. A number of these side effects have been associated with the solvents used for the dilution of these antineoplastic agents: $\mathrm{CrEL}^{2}$ for paclitaxel and polysorbate 80 (Tween 80 ) for docetaxel, respectively; specifically the acute hypersensitivity infusion reactions and peripheral neuropathy $(\mathrm{PN})$. CrEL and Tween 80 are used as solvents for a number of other hydrophobic pharmacologic agents such as diazepam, propofol, cyclosporine and etoposide. ${ }^{3}$ In addition, several reports have linked the solvents to the alterations in paclitaxel and docetaxel pharmacokinetic profiles. ${ }^{3}$ In recent years, extensive research has been focused on discovery of novel second-generation taxanes (Table 1), and other nontaxane microtubule-targeting chemotherapies (Table 2) with the goal to increase their selectivity, efficacy, and central nervous system penetrance and to decrease toxicity and the development of drug resistance. Several different strategies were developed to create new formulations of paclitaxel and docetaxel including the utilization of albumin nanoparticles, development of drug analogs, prodrugs, polyglutamate emulsions, and others. At least nine new taxanes underwent clinical trials in the last decade (Table 1). An albuminbound 130-nm nanoparticle form of paclitaxel; ( $n a b^{\mathrm{TM}}$, Celgene) paclitaxel or Abraxane was US Food and Drug Administration (FDA)-approved in 2005 for the treatment of refractory, metastatic, or relapsed breast cancer. More recently, cabazitaxel was also FDA-approved in 2010 for the treatment of hormone-refractory metastatic prostate cancer in patients previously treated with a docetaxel-containing regimen. In this article, we will focus on the new taxane formulations and analogs which are FDA-approved or still in clinical development for the treatment of various solid tumor malignancies.

\section{Nanoparticle albumin-bound paclitaxel \\ Formulation}

Nanoparticle albumin-bound paclitaxel ( $n a b$ paclitaxel; ABI 007 or Abraxane ${ }^{\circledR}$; Celgene Inc, Odenton, MD) is a colloidal suspension prepared by homogenization of human serum albumin at a concentration of 3\%-4\% with paclitaxel. ${ }^{4}$ The resulting nanoparticle has a small diameter and facilitates enhanced intracellular antitumor paclitaxel delivery and activity. ${ }^{4,5}$ Abraxane is CrEL-free and therefore premedication with steroids is not usually required. In addition $n a b$ paclitaxel can be prepared in standard plastic intravenous infusion bags, since it is not associated with the risk of leaking plasticizers from the infusion bags or tubing like CrEL-paclitaxel. Abraxane can also be reconstituted in a much smaller volume of normal saline compared to paclitaxel and therefore it is approved at $260 \mathrm{mg} / \mathrm{m}^{2}$ every 3 weeks to be infused over a shorter period of time (30 minutes) as opposed to the standard 180 minutes infusion durations of CrEL-paclitaxel. ${ }^{4}$

\section{Activity}

In Phase I studies, the maximum-tolerated dose (MTD) of Abraxane intravenously was established to be $300 \mathrm{mg} / \mathrm{m}^{2}$ for the every 3 -week schedule 4 , and $150 \mathrm{mg} / \mathrm{m}^{2}$ for the weekly schedule, 3 weeks on and 1 week off; for both schedules, these doses are generally higher than for CrEL-paclitaxel. In 2005, the US FDA approved the use of Abraxane for the treatment of metastatic breast cancer (MBC) based on a randomized, controlled trial (RCT) in patients with MBC who received either $n a b$ paclitaxel or CrEL-paclitaxel intravenously every 3 weeks at a dose of $260 \mathrm{mg} / \mathrm{m}^{2}$ and $175 \mathrm{mg} / \mathrm{m}^{2}$ respectively. The primary objective of this study was to demonstrate non-inferiority of $n a b$ paclitaxel when compared to $\mathrm{CrEL}$-paclitaxel. Based upon an intention-totreat analysis, Abraxane showed significant improvements in the response rates (RR) compared to paclitaxel (33\% vs $19 \%$, respectively; $P=0.001)$ and in the time to progression (TTP) (23 vs 16.9 weeks, respectively; hazard ratio $[\mathrm{HR}]=0.75 ; P=0.006)$. There was also a trend for greater median survival for all patients treated with Abraxane than with paclitaxel that did not reach statistical significance (65 vs 55.7 weeks, respectively; $P=0.374$ ); however, this difference was statistically significant in patients who received Abraxane as a second-line or greater therapy (56.4 vs 46.7 weeks, respectively; $P=0.024){ }^{6}$ Recently Gradishar et al published a Phase II study in patients with 
previously untreated $\mathrm{MBC}$ who received three different Abraxane regimens $\left(300 \mathrm{mg} / \mathrm{m}^{2}\right.$ every 3 weeks, $100 \mathrm{mg} / \mathrm{m}^{2}$ weekly or $150 \mathrm{mg} / \mathrm{m}^{2}$ weekly, 3 weeks on, 1 week off) or docetaxel $100 \mathrm{mg} / \mathrm{m}^{2}$ every 3 weeks and showed that weekly Abraxane $\left(150 \mathrm{mg} / \mathrm{m}^{2} /\right.$ week $)$ was superior to other treatment arms in this study; and also yielded longer progressionfree survival (PFS) than docetaxel every 3 weeks (12.9 vs 7.5 months, respectively; $P=0.0065) .^{7}$ More recently, a Phase III Cancer and Leukemia Group B 40502/North Central Cancer Treatment Group N063H 2012 American Society of Clinical Oncology (ASCO) annual meeting. ${ }^{8}$ Chemotherapy-naïve $(N=799)$ patients with $\mathrm{MBC}$, were randomized 1:1:1 to receive CrEL-paclitaxel $\left(90 \mathrm{mg} / \mathrm{m}^{2}\right)$ or $n a b$ paclitaxel $\left(150 \mathrm{mg} / \mathrm{m}^{2}\right)$ or ixabepilone $\left(16 \mathrm{mg} / \mathrm{m}^{2}\right)$ on a 3 weeks on and 1 week off schedule. Patients were stratified by prior adjuvant taxane use and hormone receptor status. Bevacizumab was initially given to all patients but became optional in March 2012. Median PFS was 10.4, 9.6, and 7.6 months for CrEL-paclitaxel, nab paclitaxel, and ixabepilone, respectively. With the PFS as the primary endpoint, this study failed to show superiority of ixabepilone or $n a b$ paclitaxel over CrEL-paclitaxel in the first-line setting in $\mathrm{MBC}$, while toxicity was higher in each experimental arm compared to CrEL-paclitaxel.

\section{Toxicity}

Compared to conventional paclitaxel, ${ }^{6}$ Abraxane was associated with lower incidence of grade 4 neutropenia ( $22 \%$ vs $9 \%$, respectively; $P<0.001$ ). Grade 3 sensory neuropathy was more common in the Abraxane treated patients compared to the paclitaxel arm ( $10 \%$ vs $2 \%$, respectively; $P<0.001)$. The incidence of hypersensitivity reactions was low in both $\operatorname{arm}(<1 \%$ for Abraxane and $2 \%$ for paclitaxel). Only $8 \%$ of the patients in the Abraxane arm received corticosteroids and antihistamines for emesis, myalgia/arthralgia, or anorexia compared to $99 \%$ of the patients in the paclitaxel arm. For the weekly schedules of $n a b$ paclitaxel vs CrEL-paclitaxel vs ixabepilone, Grade $2+$ sensory neuropathy was $48 \%, 37 \%$, and $44 \%$, and grade $3+$ hematologic toxicity was $49 \%, 12 \%$, and $20 \%$, respectively. ${ }^{8}$ Compared to docetaxel, Abraxane was associated with much lower incidence of grade 4 neutropenia ( $75 \%$ vs $<10 \%$, respectively; $P<0.001){ }^{7}$ Febrile neutropena was also more frequent in the docetaxel $\operatorname{arm}(8 \%$ vs $1 \%$ respectively). The incidence of sensory PN was comparable between docetaxel and Abraxane, but the neuropathy symptoms resolved more rapidly after treatment with Abraxane compared to docetaxel.

\section{Cabazitaxel}

\section{Formulation}

Cabazitaxel (Jevtana ${ }^{\circledR}$, previously known as XRP6258, TXD258, and RPR116258A, Sanofi) is a semisynthetic dimethyloxy derivative of docetaxel engineered to potentially have clinical and pharmacokinetic advantages over its precursor docetaxel. This is potentially provided by the alteration in the structure of the docetaxel backbone and substitution of the hydroxyl groups by the dimethyloxy side chains causing alteration of the P-glycoprotein (P-gp) affinity characteristic of docetaxel which is thought to be responsible in part for the development of resistance to docetaxel and other taxanes. Furthermore the presence of the extra methyloxy side chains theoretically elicits the ability of cabazitaxel to cross the blood-brain barrier.

\section{Activity}

In a Phase I dose escalation study in solid tumor malignancies of cabazitaxel (10-25 mg/m², 1 hour infusion every 3 weeks), the recommended dose for Phase II development was $20 \mathrm{mg} / \mathrm{m}^{2}$ every 3 weeks. Clinically relevant responses were seen in patients with hormone refractory prostate cancer however prolonged neutropenia and febrile neutropenia were seen in the $25 \mathrm{mg} / \mathrm{m}^{2}$ cohort and were considered dose limiting. ${ }^{9}$ In 2010, the FDA approved the use of cabazitaxel for the treatment of patients with hormone-refractory metastatic prostate cancer previously treated with a docetaxel-containing regimen based on the pivotal multicenter Phase III RCT, TROPIC (treatment of hormone-refractory metastatic prostate cancer previously treated with a docetaxel-containing regimen). ${ }^{10}$ Patients were randomized to cabazitaxel $\left(25 \mathrm{mg} / \mathrm{m}^{2}\right)$ or mitoxantrone $\left(12 \mathrm{mg} / \mathrm{m}^{2}\right)$ intravenously every 3 weeks. Impressively, the median overall survival (OS), which was the primary endpoint of this study, was significantly better in the cabazitaxel arm (15.1 months) compared to 12.7 months in the mitoxantrone $\operatorname{arm}(P<0.001)$. The median PFS doubled from 1.4 months in the mitoxantrone arm to 2.8 months in the cabazitaxel arm $(P<0.001)$. There were also significant improvements in the tumor response rates, however pain reduction was similar in both patient groups.

\section{Toxicity}

In the cabazitaxel arm of the TROPIC trial, ${ }^{10} 82 \%$ of men experienced grade 3 neutropenia, $8 \%$ experienced febrile neutropenia, and 14\% reported all grades of PN. However, only $1 \%$ of the patients in each group experienced grade 3 PN. $47 \%$ had all grades of diarrhea, and $17 \%$ all grades 
Table I Novel taxane formulations

\begin{tabular}{|c|c|c|c|c|}
\hline Name & Manufacturer & Development stage & Delivery strategy & Potential indications \\
\hline $\begin{array}{l}\text { Cabazitaxel } \\
\left(\text { Jevtana }^{\circledR}\right)\end{array}$ & Sanofi & $\begin{array}{l}\text { FDA-approved (2010, prostate) } \\
\text { Phase II in BC }\end{array}$ & $\begin{array}{l}\text { Semisynthetic derivative } \\
\text { of a natural taxoid }\end{array}$ & $\begin{array}{l}\text { Prostate } \\
\text { Breast }\end{array}$ \\
\hline
\end{tabular}

\begin{tabular}{|c|c|c|c|c|}
\hline $\begin{array}{l}\text { Nab-paclitaxel } \\
\left(\text { Abraxane }{ }^{\circledR}\right)\end{array}$ & $\begin{array}{l}\text { Abraxis bioscience/ } \\
\text { Celgene }\end{array}$ & $\begin{array}{l}\text { FDA-approved (2005, breast) } \\
\text { Phase II in lung, pancreas and } \\
\text { ovarian }\end{array}$ & $\begin{array}{l}\text { Nanoparticles, } \\
\text { albumin-bound }\end{array}$ & $\begin{array}{l}\text { Breast } \\
\text { NSCLC } \\
\text { Pancreas } \\
\text { Ovarian }\end{array}$ \\
\hline $\begin{array}{l}\text { DJ-927 } \\
\left(\text { Tesetaxel }^{\circledR}\right)\end{array}$ & Genta & Phase II & Analog & $\begin{array}{l}\text { Breast } \\
\text { Gastroesophageal } \\
\text { Melanoma } \\
\text { Bladder } \\
\text { NSCLS }\end{array}$ \\
\hline $\begin{array}{l}\text { Paclitaxel } \\
\text { poliglumex/CT-2103 } \\
\left(\text { Opaxio }^{\circledR}\right)\end{array}$ & Cell therapeutics & $\begin{array}{l}\text { Phase III NSCLC, } \\
\text { ovarian and glioblastoma }\end{array}$ & $\begin{array}{l}\text { Prodrug } \\
\text { Macromolecule, water-soluble } \\
\text { polymer of glutamic acid, } \\
\text { linked to paclitaxel }\end{array}$ & $\begin{array}{l}\text { NSCCL (phase III in PS2 } \\
\text { naïve), } \\
\text { ovarian (phase II), } \\
\text { glioblastoma, } \\
\text { esophageal (phase II) }\end{array}$ \\
\hline $\begin{array}{l}\text { EndoTAG + } \\
\text { paclitaxel } \\
\left(\text { EndoTAG }{ }^{\circledR}-\mathrm{I}\right)\end{array}$ & MediGene & $\begin{array}{l}\text { Phase II pancreatic with Gem } \\
\text { TNBC }\end{array}$ & $\begin{array}{l}\text { Cationic } \\
\text { Liposomal } \\
\text { paclitaxel }\end{array}$ & $\begin{array}{l}\text { Pancreas } \\
\text { Breast }\end{array}$ \\
\hline $\begin{array}{l}\text { XRP988I } \\
\left.\text { (Larotaxel }^{\circledR}\right)\end{array}$ & Sanofi & $\begin{array}{l}\text { Phase II } \\
\text { NSCLC with Cis or Gem } \\
\text { Breast }\end{array}$ & Analog & $\begin{array}{l}\text { NSCLC } \\
\text { Breast }\end{array}$ \\
\hline $\begin{array}{l}\text { Polymeric-micellar } \\
\text { paclitaxel } \\
\left(\text { Genexol-PM }{ }^{\circledR}\right)\end{array}$ & Samyang Genex Co & $\begin{array}{l}\text { Phase II } \\
\text { NSCLC with Cis or Carbo } \\
\text { Breast } \\
\text { Gastric }\end{array}$ & C0-solvents, Cremophor-free & $\begin{array}{l}\text { NSCLC } \\
\text { Breast } \\
\text { Gastric }\end{array}$ \\
\hline $\begin{array}{l}\text { DHA-paclitaxel } \\
\left(\text { Taxoprexin }^{\circledR}\right)\end{array}$ & Protarga & $\begin{array}{l}\text { Completed phase III NSCLC } \\
\text { with carbo } \\
\text { Completed phase III melanoma }\end{array}$ & Prodrug & $\begin{array}{l}\text { NSCLC } \\
\text { Melanoma } \\
\text { GE junction }\end{array}$ \\
\hline $\begin{array}{l}\text { BMS-184476 } \\
\text { (last publication } \\
\text { in 2005) }\end{array}$ & Bristol-Myers-Squibb & $\begin{array}{l}\text { Phase I/II NSCLC alone, or } \\
\text { in combination with cisplatin, } \\
\text { carboplatin or adriamycin }\end{array}$ & $\begin{array}{l}\text { Analogs } \\
\text { CrEL }\end{array}$ & $\begin{array}{l}\text { NSCLC } \\
\text { Breast }\end{array}$ \\
\hline
\end{tabular}

Abbreviations: EMA, European Medicines Agency; FDA, US Food and Drug Administration; IV, intravenous; NSCLC, non-small-cell lung cancer; TNBC, triple negative breast cancer; CRC, colorectal cancer; GE junction- gastro-esophageal junction; PS2-ECOG performance status 2. 


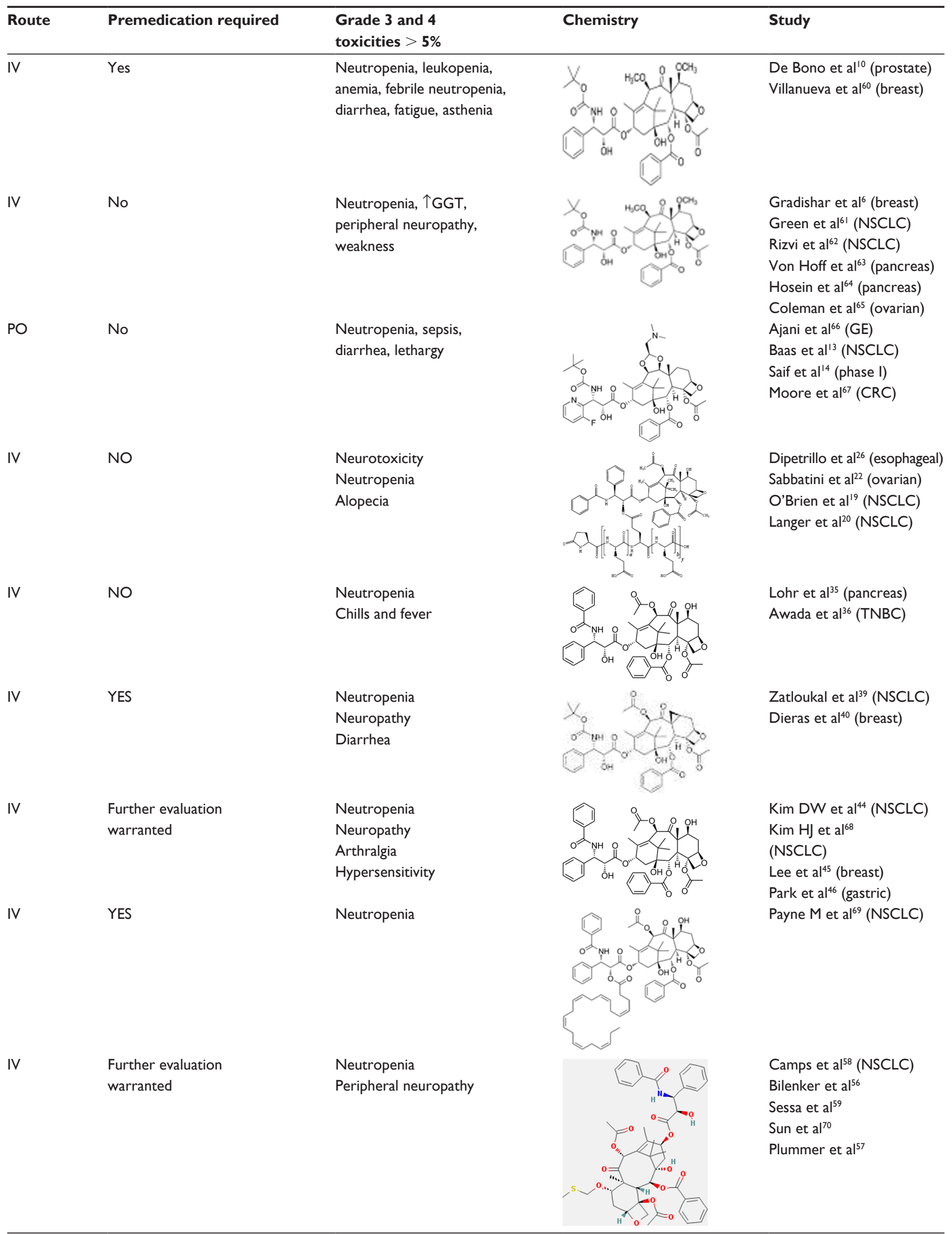


Table 2 Novel nontaxane microtubule-targeting agents

\begin{tabular}{llll}
\hline Name & Manufacturer & Development stage & Mechanisms of action \\
\hline $\begin{array}{l}\text { Eribulin } \\
\left(\text { Halaven }^{\circledR}\right)\end{array}$ & Eisai Co & FDA-approved (20I0, breast) & Analog of the marine sponge natural \\
& & & product halichondrin B: mechanistically- \\
& & & unique inhibitor of microtubule dynamics
\end{tabular}

Ixabepilone Bristol-Myers-Squibb FDA-approved (2007, breast) Bpothilones (stabilize microtubule)

(Ixempra ${ }^{\circledR}$ )

Vinflunine

Bristol-Myers-Squibb

EMA-approved (2009, urothelial)

Phase III in NSCLC

Vinca alkaloids (prevent microtubule

assembly)

Urothelial

NSCLC

Note: *In association with Capecitabine.

Abbreviations: EMA, European Medicines Agency; FDA, US Food and Drug Administration; IV, intravenous; NSCLC, non-small-cell lung cancer.

of hematuria. In the TROPIC trial a relatively high rate of cabazitaxel-related mortality was noted: 18 patients $(5 \%)$ died from neutropenia/sepsis (seven patients), cardiac events (five patients), renal failure (three patients), dehydration (one patient), cerebral hemorrhage (one patient), and unknown cause (one patient). ${ }^{10}$ Based on this data, the FDA label recommends the use of primary prophylaxis of growth factor support in patients who are at high risk for myelosuppression. ${ }^{11}$ Careful patient selection and monitoring are crucial, and dose-reductions to $20 \mathrm{mg} / \mathrm{m}^{2}$ may often be necessary.

\section{DJ-927 \\ Formulation}

DJ-927 (XRP6258, XRP9881, Tesetaxel ${ }^{\circledR}$, Genta Inc, Berkeley Heights, NJ) is a novel orally bioavailable semisynthetic taxane derivative with high solubility, lack of neurotoxicity and impressive antitumor activity. Efficacy of DJ-927 was compared in vitro and in vivo to paclitaxel and docetaxel and DJ-927 was found to be more potent with higher cytotoxicity than paclitaxel and docetaxel in various tumor cell lines, but especially in P-gp-expressing tumor cell lines. Unlike other taxanes, the tumoricidal efficacy of DJ-927 was unaffected by the P-gp expression levels or by the expression of a P-gp modulator. In addition the intracellular accumulation of DJ-927 was much higher than those of paclitaxel or docetaxel, particularly in P-gppositive cells. ${ }^{12}$ Pharmacokinetic analysis in a human Phase I study with DJ-927 $27 \mathrm{mg} / \mathrm{m}^{2}$ orally every 3 weeks showed that the median area under the curve $(\mathrm{t}=0-168$ hours) was $1752 \pm 1355 \mathrm{ng} / \mathrm{mL} /$ hour and the half-life was $167 \pm 77$ hours. $^{13}$

\section{Activity}

In a Phase I/II study of DJ-927 (Daiichi Pharmaceutical Co, Ltd, Edogawa-ku, Tokyo, Japan) taxane-naïve patients with recurrent, advanced NSCLC received a single oral dose of DJ-927 $\left(27 \mathrm{mg} / \mathrm{m}^{2}\right)$ every 3 weeks and if tolerated further dose escalation to $35 \mathrm{mg} / \mathrm{m}^{2}$ was acceptable. The majority of 36 patients received cisplatin and gemcitabine before entering this study, the overall response rate was $5.6 \%, 47 \%$ of patients had disease stabilization for $>6$ weeks, median TTP was 97 days, and the median survival time 120 days. ${ }^{13}$ Based on the results of this study, it was felt that combinations with other cytotoxic agents or other schedules such as metronomic schedule, can be considered for further development, however the activity in patients with minimally pretreated NSCLC was disappointingly low in this study. Another Phase I study of DJ-927 was performed in combination with capecitabine in patients with advanced solid tumor malignancies. Patients $(N=27)$ received DJ-927 on Day 1 and capecitabine twice daily on Days 1 through 14. The starting dose was DJ-927 $18 \mathrm{mg} /$ $\mathrm{m}^{2}$ and capecitabine $1,250 \mathrm{mg} / \mathrm{m}^{2} /$ day with the plan to escalate the dose if tolerated and based on a prespecified protocol dose escalation schema. The best overall response was stable disease (SD) in $82 \%$ of patients. No meaningful pharmacokinetic drug interactions were appreciated in this study and this combination of the novel oral taxane DJ-927 tesetaxel with capecitabine was felt to be well tolerated with acceptable toxicities and further clinical development was recommended. ${ }^{14}$ 


\begin{tabular}{|c|c|c|c|c|}
\hline Route & Premedication required & Grade 3 and 4 toxicities $>5 \%$ & Chemistry & Study \\
\hline IV & No & $\begin{array}{l}\text { Neutropenia } \\
\text { Fatigue } \\
\text { Peripheral neuropathy }\end{array}$ & & Cortes J et al ${ }^{71}$ (breast) \\
\hline IV & Yes & $\begin{array}{l}\text { Peripheral neuropathy } \\
\text { Hand-foot syndrome* } \\
\text { Febrile neutropenia* }\end{array}$ & & $\begin{array}{l}\text { Thomas } \mathrm{E} \text { et } \mathrm{al}^{72} \text { (breast) } \\
\text { Sparano J et al }{ }^{73} \text { (breast) }\end{array}$ \\
\hline IV & No & $\begin{array}{l}\text { Anemia, leukopenia, neutropenia, } \\
\text { constipation and fatigue }\end{array}$ & & $\begin{array}{l}\text { Bellmunt et } \mathrm{a}^{74} \\
\text { (urothelial) } \\
\text { Krzakowski et al }{ }^{75} \\
\text { (NSCLC) }\end{array}$ \\
\hline
\end{tabular}

\section{Toxicity}

In minimally pretreated patients with NSCLC, the majority of patients did not tolerate the $35 \mathrm{mg} / \mathrm{m}^{2}$ or higher dose of DJ-927 due to hematological toxicities. The most common Grade $3 / 4$ toxicities for the $27 \mathrm{mg} / \mathrm{m}^{2}$ oral dose every 21 days included neutropenia (53\%), anemia (18\%), nausea and fatigue $(6 \%)$ but febrile neutropenia and neurotoxicity were rare $(3 \%) .{ }^{13}$ For the combination of DJ-927 with capecitabine, the most common dose-limiting toxicities (DLTs) were neutropenia, febrile neutropenia, stomatitis, and diarrhea. The MTD for the treatment regimen was defined as DJ-927-tesetaxel $27 \mathrm{mg} / \mathrm{m}^{2}$ and capecitabine $2,500 \mathrm{mg} /$ $\mathrm{m}^{2} /$ day. The most common $\geq$ Grade 3 treatment-related toxicities for this combination included leukopenia (44\%) and neutropenia $(41 \%){ }^{14}$

\section{Paclitaxel poliglumex Formulation}

Paclitaxel poliglumex (PPX) or CT-2103 (previous trade name Xytotax ${ }^{\circledR}$ currently known as Opaxio $\left.{ }^{\circledR}\right)($ Cell Therapeutics, Inc, Seattle, WA) is a novel biodegradable polymeric drug conjugate of paclitaxel with $\alpha$-poly-L-glutamic acid. It is designed to enhance the solubility of hydrophobic paclitaxel and its selective tumor permeability, to minimize normal tissue exposure to free drug, and to evade the multidrug resistance (MDR) efflux pumps. ${ }^{15}$ This novel formulation of paclitaxel does not contain CrEL and therefore premedication with steroids and antihistamines is not required, and this compound can be safely infused in a peripheral vein over 10-20 minutes every 3 weeks.

\section{Activity}

PPX was studied as a single agent, in combination with other chemotherapy drugs, and with radiotherapy. In Phase I dose escalation studies as a single agent, the recommended dose of PPX was $235 \mathrm{mg} / \mathrm{m}^{2}$ over 10 minutes every 3 weeks ${ }^{16,17}$ or $70 \mathrm{mg} / \mathrm{m}^{2}$ weekly. ${ }^{18}$ The PPX compound was extensively explored in NSCLC and compared to other agents with known activity in advanced NSCLC. In chemotherapy-naïve patients with advanced NSCLC with poor performance status (PS 2), PPX was compared to gemcitabine or vinorelbine and showed equivalent efficacy with less myelotoxicity, but more neurotoxicity. ${ }^{19}$ In combination with carboplatin, PPX failed to provide superior survival compared with paclitaxel/ carboplatin in the first-line treatment of PS 2 patients with NSCLC, although the PPX + carboplatin combination was more convenient due to shorter infusion time of PPX compared to paclitaxel (10 minutes vs 3 hours) and lack of routine steroid premedication with PPX. ${ }^{20}$ When compared to docetaxel in the second-line treatment of NSCLC, PPX produced similar survival rates with reduced alopecia, grade 3-4 neutropenia and febrile neutropenia, but increased grade 3-4 neurotoxicity rates. ${ }^{21}$ PPX also showed interesting activity in advanced ovarian carcinoma, ${ }^{22}$ and is currently being tested in comparison to paclitaxel or observation as a maintenance strategy in ovarian cancer. ${ }^{23}$ As a radiosensitizer, PPX was combined with temozolomide for the treatment of high-grade gliomas and showed promising results, with a median PFS of 12.5 months. ${ }^{24}$ A Phase II trial of PPX and concurrent radiation for newly diagnosed glioblastoma without $\mathrm{O}$ 6-methylguanine-DNA methyltransferase methylation is 
ongoing. ${ }^{25}$ Neoadjuvant concurrent PPX, cisplatin and radiotherapy combination therapy for esophageal carcinoma was well tolerated and yielded high pathologic complete response $(\mathrm{CR})$ of $32 \%{ }^{26}$

\section{Toxicity}

As stated above, neurotoxicity was common with PPX, but grade 3-4 neuropathy was uncommon $(<5 \%) .{ }^{19}$ Grade 3 neutropenia was the DLT in early Phase I studies. ${ }^{18}$ Hypersensitivity reactions were unexpectedly high in MBC patients. $^{27}$

\section{Cationic liposomal paclitaxel (EndoTAG-I)}

\section{Formulation}

Cationic liposomal paclitaxel or EndoTAG-1 which does not contain CrEL was designed with the same concept in mind as liposomal doxorubicin, with the ultimate goal of improved efficacy and toxicity profile over the parent compound CrEL-paclitaxel. In addition preclinical data for EndoTAG-1 showed that cationic liposomes target angiogenic endothelial cells in tumors; ${ }^{28}$ EndoTAG-1 was implicated in being able to affect tumor microvasculature by causing functional impairment, ${ }^{29}$ tumor-selective vessels occlusion, ${ }^{30}$ and microvessel leakiness which potentially may improve its therapeutic efficacy in combination with other chemotherapy agents. ${ }^{31}$ These antiangiogenic characteristics confer another advantage of EndoTAG over conventional paclitaxel. $^{32}$

\section{Activity}

In xenograft mouse model, EndoTAG-1 produced a prostate cancer tumor shrinkage that was significantly more pronounced than conventional paclitaxel. ${ }^{33}$ In another preclinical study, the combination of EndoTAG-1 with gemcitabine and cisplatin had significantly enhanced antitumoral efficacy and inhibited the incidence of metastasis in pancreatic cancer. ${ }^{34} \mathrm{~A}$ Phase II RCT of gemcitabine \pm EndoTAG-1 showed that the combination of gemcitabine with EndoTAG-1 in chemotherapy-naïve locally advanced or metastatic pancreatic cancer was well tolerated with improved disease-control rate, PFS and OS compared to gemcitabine alone. ${ }^{35}$ In another Phase II study, patients with advanced triple-negative breast cancer treated with the combination of conventional paclitaxel + EndoTAG-1 had longer PFS compared to either EndoTAG-1 or paclitaxel alone PFS at 16 weeks was $59 \%$ in the combination arm and $34 \%$ and $48 \%$ in the EndoTAG-1 and paclitaxel arms, respectively. ${ }^{36}$

\section{Toxicity}

A tolerable toxicity profile was reported in the Phase II trials; the more commonly described side effects included fatigue, hypersensitivity reactions, neutropenia, fever, and chills.

\section{Larotaxel}

\section{Formulation}

Larotaxel (XRP9881, Sanofi) is a novel semisynthetic taxoid derived from 10-deacetyl baccatin III, which is the major natural compound of the yew tree needles. As other taxanes, it is a tubulin-targeting drug that causes a defect in the mitotic spindle assembly. The focus of development of larotaxel has been its ability to cross the blood-brain barrier ${ }^{37}$ and its activity in both taxane-sensitive and -resistant cell lines in preclinical studies. ${ }^{38}$

\section{Activity}

The most well-studied single-agent dose schedule is $90 \mathrm{mg} / \mathrm{m}^{2}$ intravenously (IV) every 3 weeks. The efficacy and the safety of larotaxel were studied in a randomized Phase II trial in combination with either cisplatin or gemcitabine in the frontline treatment of stage $3 \mathrm{~B}$ or 4 NSCLC. The RR, PFS, and OS were higher in the larotaxel + cisplatin compared to larotaxel + gemcitabine combinations (RR: $26.7 \%$ vs $18.2 \%$, PFS: 4.7 vs 3.3 months, and OS: 8.6 vs 7.3 months, respectively). ${ }^{39}$ Larotaxel was also evaluated in another Phase II trial, alone in taxane-sensitive and -resistant advanced breast cancer patients and showed a respectable activity with an objective response rate ORR of $42 \%$, and a median TTP of 5.4 months in the taxane-sensitive group, but only minimal efficacy with an ORR of $19 \%$, and a median TTP of 1.6 months in the taxane-resistant group. ${ }^{40}$

\section{Toxicity}

The most common toxicities for single agent Larotaxel therapy reported by Dieras et al included a very high incidence of grade 3-4 neutropenia ( $82 \%$ ), followed by fatigue $(15 \%)$, diarrhea (12\%), febrile neutropenia (9\%), and sensory neuropathy $(7 \%) .{ }^{40}$ In combination with cisplatin or gemcitabine, the most common grade 3-4 side effect was neutropenia as well, with more than half of the patients experiencing at least one grade 3-4 adverse event. ${ }^{39}$

\section{Polymeric-micellar paclitaxel Formulation}

Polymeric-micellar paclitaxel or Genexol-PM ${ }^{\circledR}$ (Samyang Genex, South Korea) is another novel taxane analog formulation of paclitaxel with a biodegradable polymericmicellar nanoparticle. ${ }^{41}$ Theoretically, the copolymer residue 
increases the water solubility of the hydrophobic paclitaxel and permits delivery of high doses of paclitaxel. In vitro, its antitumor effect was more pronounced than conventional CrEL-paclitaxel in a variety of tumor cell lines. ${ }^{41-43}$

\section{Activity}

In a multicenter Phase II study, the Genexol-PM + cisplatin combination was tested in advanced NSCLC as first-line therapy; it showed good activity (ORR: 37.7\%) and allowed administration of higher doses of paclitaxel - up to $300 \mathrm{mg} / \mathrm{m}^{2}$ every 3 weeks - compared to conventional paclitaxel without significantly increasing the toxicities ${ }^{44}$ However in this study, cisplatin was given at a dose of $60 \mathrm{mg} / \mathrm{m}^{2}$ every 3 weeks, which is lower than the conventional cisplatin dose given in other combination chemotherapy regimens for NSCLC. GenexolPM alone, at a dose of $300 \mathrm{mg} / \mathrm{m}^{2}$ every 3 weeks, was also tested in another multicenter Phase II study in advanced breast cancer and showed significant activity; the ORR was $59.5 \%$ and the median TTP of 9.0 months. ${ }^{45}$ Genexol $175 \mathrm{mg} / \mathrm{m}^{2}$ plus cisplatin $75 \mathrm{mg} / \mathrm{m}^{2}$ combination every 3 weeks was also studied in previously untreated advanced gastric cancer; $46 \%$ of the patients achieved a partial response and $20 \%$ had stable disease with a median TTP of 4.9 months. ${ }^{46}$

\section{Toxicity}

Myelotoxicity, peripheral neuropathy, and hypersensitivity reactions were the most common side effects of this agent. Lee et al reported grade 3-4 neutropenia in $68.3 \%$ of the patients when Genexol-PM was used alone but without the associated risk of febrile neutropenia. ${ }^{45} \mathrm{Kim}$ and colleagues reported grade 3-4 neutropenia in $46.4 \%$ of the patients with NSCLC treated with the combination of Genexol-PM + cisplatin. ${ }^{44}$ Grade 3 sensory PN rate was reported in $51.2 \%$ of patients in the breast cancer trial, mostly after the sixth cycle of treatment; ${ }^{45}$ however, the authors did not provide data about the prior exposure to taxanes in the adjuvant or metastatic settings. On the other hand, Genexol-PM in combination with cisplatin resulted in grade 3-4 PN in only $9 \%$ and $13 \%$ of gastric ${ }^{46}$ and lung ${ }^{44}$ cancer patients, respectively. All grade hypersensitivity reactions were seen in $19.5 \%$ of the cases ${ }^{45}$ whereas grade $3-4$ hypersensitivity reactions were uncommon $(5.8 \%) .{ }^{44}$ Grade alopecia was seen in less than $10 \%$ of the cases.

\section{DHA-paclitaxel (Taxoprexin ${ }^{\circledR}$ )}

\section{Formulation}

A natural fatty acid, docosahexaenoic acid (DHA) was conjugated through an ester bond to the paclitaxel 2 '-oxygen with the resulting paclitaxel fatty acid conjugate (DHApaclitaxel). The premise for this was the hypothesis that certain natural fatty acids are taken up avidly by tumors for use as biochemical precursors and energy sources. This hypothesis was eventually tested via conjugation of DHA, a natural fatty acid, and paclitaxel to create a new chemical entity that could potentially target tumors better and reduce toxicity to normal tissues. ${ }^{47,48}$ In the M109 mouse tumor model, DHA-paclitaxel was less toxic than paclitaxel and with greater therapeutic index possibly due to the alteration of the pharmacokinetics of the drug by the fatty acid and to increased area under the curve (AUC) in tumors and decreased AUC in normal cells. The concentrations of paclitaxel and DHA-paclitaxel were analyzed in vivo in mouse models (M109) and showed that DHA delivers paclitaxel to tumors; tumor AUCs were 61-fold higher for DHA-paclitaxel than for paclitaxel at equitoxic doses and eightfold higher at equimolar doses. ${ }^{47}$ These findings were consistent with the increase in therapeutic index of DHA-paclitaxel relative to paclitaxel. DHA-paclitaxel-Taxoprexin is formulated for human injection as a 2-hour infusion in a vehicle that contains $81 \%$ less CrEL than conventional paclitaxel on a molar basis. The blood distribution of DHA-paclitaxel was assessed in 23 cancer patients receiving the drug as a 2-hour IV infusion (dose, 200-1100 mg/m²). In vitro, DHApaclitaxel was found to bind extensively to human plasma (99.6 \pm 0.057$)$. The binding was concentration independent, indicating a nonspecific, nonsaturable process. The fraction of unbound paclitaxel increased (relative increase, 6.25\%; $P=0.011$ ) with an increase in DHA-paclitaxel concentration, suggesting weakly competitive drug displacement from protein-binding sites. The mean ( \pm standard deviation) area under the curve of unbound paclitaxel increased nonlinearly with dose from $0.089 \pm 0.029 \mu \mathrm{g} \cdot$ hour $/ \mathrm{mL}$ (at $660 \mathrm{mg} / \mathrm{m}^{2}$ ) to $0.624 \pm 0.216 \mu \mathrm{g} \cdot$ hour $/ \mathrm{mL}$ (at $1100 \mathrm{mg} / \mathrm{m}^{2}$ ), and was associated with the dose-limiting neutropenia. A comparative analysis indicates that exposure to $\mathrm{CrEL}$ and unbound paclitaxel after DHA-paclitaxel (at $1100 \mathrm{mg} / \mathrm{m}^{2}$ ) is similar to that achieved with paclitaxel on clinically relevant dose schedules. Extensive binding to plasma proteins may explain, in part, the unique pharmacokinetic profile of DHA-paclitaxel described previously with a small volume of distribution (approximately $4 \mathrm{~L}$ ) and slow systemic clearance (approximately $0.11 \mathrm{~L} /$ hour). ${ }^{49}$

\section{Activity}

A Phase I clinical study was done to evaluate the safety of DHA-paclitaxel in patients with solid tumor malignancies. 
The recommended Phase II dose was $1100 \mathrm{mg} / \mathrm{m}^{2}$, which is equivalent to 4.6 times the maximum approved paclitaxel dose on a molar basis. Eleven of 22 evaluable patients had stable disease with significant quality-of-life improvements and the DHA-paclitaxel was well tolerated in these patients. ${ }^{47}$ Another dose escalation study to determine the maximum tolerated dose, DLT, and pharmacokinetics of DHA-paclitaxel as 2-hour IV infusion weekly for three out of four weeks was done. DHA-paclitaxel starting dose of $200 \mathrm{mg} / \mathrm{m}^{2}$ was dose escalated to $600 \mathrm{mg} / \mathrm{m}^{2} .^{50}$ Pharmacokinetics of DHApaclitaxel and paclitaxel derived from DHA-paclitaxel were collected, grade 3-4 neutropenia occurred in five patients but was not dose limiting. Grade 3 hyperbilirubinemia was the DLT, and grade 1 sensory neuropathy occurred at the highest dose level. Pharmacokinetic analyses demonstrated dose proportional maximum concentration and AUC (0-24). Limited accumulation of DHA-paclitaxel or paclitaxel occurred with weekly treatment, increased DHA-paclitaxel and paclitaxel AUC (0-24) were associated with increased neutropenia. Of the 19 patients evaluable for response, three patients with esophageal, melanoma, and colon carcinoma had stable disease with the overall assessment that DHApaclitaxel administered weekly to a maximum dose of $600 \mathrm{mg} / \mathrm{m}^{2}$ was well tolerated. In addition, the slow release of paclitaxel from DHA-paclitaxel and the weekly schedule was felt to mimic continuous infusion paclitaxel which may be more active than three weekly or weekly infusion schedules for taxanes. ${ }^{50}$ Phase III study of DHA-paclitaxel in metastatic malignant melanoma was done, based on the premise of the initial preclinical studies showing increased activity in chemotherapy resistant solid tumors and a Phase II study showing activity in this patient population, ${ }^{51} 393$ chemotherapy-naïve patients randomly received DHApaclitaxel at a starting dose of $900 \mathrm{mg} / \mathrm{m}^{2} \mathrm{IV}$ on day 1 every 3 weeks or dacarbazine at a starting dose of $1000 \mathrm{mg} / \mathrm{m}^{2}$ IV on day 1 every 3 weeks. No significant difference in OS, RR, duration of response, TTP was noted between the DHA-paclitaxel and dacarbazine arms. Safety results of the two drugs were acceptable, myelosuppression was more common with DHA-paclitaxel. ${ }^{52}$ In the single arm, Phase II study of DHA-paclitaxel in untreated, inoperable locally advanced or metastatic adenocarcinoma of the esophagus, gastroesophageal junction or stomach, DHA-paclitaxel (1100 mg/m²) administered by 2-hour IV every 21 days was assessed with confirmed partial responses (9.4\%), DHApaclitaxel has modest activity in patients with esophagogastric cancer and with hematological toxicity that is comparable to paclitaxel and docetaxel..$^{53}$

\section{Toxicity}

In a Phase I study, no alopecia or significant peripheral neuropathy, nausea, or vomiting were observed; asymptomatic, transient neutropenia was the primary side effect. ${ }^{47}$ In a Phase II study in malignant melanoma patients, the most common grade 3-4 toxicities of DHA-paclitaxel were neutropenia (10\%), musculoskeletal pain (10\%), while fatigue (73\%), skin rash (70\%), and diarrhea (60\%) were the most common side effects. ${ }^{51}$ Neutropenia with DHApaclitaxel appears to be dose-dependent, in a Phase II study in chemotherapy-naïve patients with esophageal carcinoma, grade 3-4 neutropenia occurred in 93\% of patients, and febrile neutropenia in $17 \%$ of patients. ${ }^{53}$

\section{BMS- I 84476}

This paclitaxel analog was developed initially primarily for its higher potency and preclinical activity seen in cell lines typically resistant to conventional paclitaxel. Preclinical studies showed that BMS-184476 was not only innately more potent than paclitaxel in assays of tubulin polymerization and against taxane-sensitive neoplasms, but was also more active against tumors that were typically taxane resistant. For instance the HCT-116/MDR human colon cancer cell line which expresses multidrug resistance due to Pgp overexpression was 62-fold more resistant to paclitaxel, while only 15 -fold resistant to BMS- $184476 .{ }^{54}$ This compound was also more active than paclitaxel against tumor cells with acquired taxane resistance mediated by tubulin mutations such as human ovarian cancer cells A2780/tax22 with taxane resistance caused by a tubulin mutation which express ninefold resistance to BMS-184467 and 32-fold to paclitaxel. The potential superiority of BMS-184476 was also suggested by the results of studies of BMS-184476 against human tumor xenografts with both acquired and primary taxane resistance models.

\section{Formulation}

BMS-184476 was more soluble than conventional paclitaxel in water based solvents containing polyoxyethylated castor oil. In addition, due to its higher potency as compared to paclitaxel, a smaller quantity of BMS-184476 (threefold less) was required to formulate $1 \mathrm{mg}$ of this agent. Since CrEL is not completely inert and is felt to contribute to some undesirable characteristics of conventional paclitaxel such as hypersensitivity reactions and the nonlinear pharmacokinetics, smaller amounts of CrEL used to formulate BMS-184476 were felt to be beneficial due to improved safety, less premedication and shorter administration schedules. In a Phase I 
study, the pharmacokinetics of BMS-184476 were linear with mean $\pm \mathrm{SD}$ values for clearance, volume of distribution at steady-state, and terminal half-life were $220 \pm 89 \mathrm{~mL} / \mathrm{min} / \mathrm{m}^{2}$, $402 \pm 231 \mathrm{~L} / \mathrm{m}^{2}$, and $40.8 \pm 21.8$ hours, respectively. ${ }^{54}$ Preclinical studies were conducted and demonstrated that the BMS-184476 can enhance the effects of radiation in human lung cancer cells both in vitro and in vivo and also supported the hypothesis that a G2/M block is involved in the radiosensitization caused by the taxanes. ${ }^{55}$

\section{Activity}

BMS-184476 was tested as single agent and in combination with other chemotherapy agents. In a Phase I dose escalation study patients with advanced solid malignancies were treated with escalating doses of BMS-184476 as a 1-hour IV infusion every 3 weeks without premedication to prevent hypersensitivity reactions (HSR) at five dose levels ranging from 20 to $80 \mathrm{mg} / \mathrm{m}^{2}$. DLT, such as neutropenic fever, severe diarrhea, and severe mucositis, were seen at the 70 and $80 \mathrm{mg} / \mathrm{m}^{2}$ dose levels. Only one patient developed a grade 2 HSR during a second course of BMS-184476 at the $40 \mathrm{mg}$ / $\mathrm{m}^{2}$ dose level. Responses were seen in untreated advanced cholangiocarcinoma, and carcinoma of the gastroesophageal junction. The recommended Phase II dose of BMS-184476 was $60 \mathrm{mg} / \mathrm{m}^{2}$ as a 1-hour IV infusion every 3 weeks. BMS-184476 was studied in combination with carboplatin and was well tolerated at a dose of 50/AUC 6 and showed evidence of antitumor activity in a heavily pretreated patient population. DLT at 60/AUC 6 was neutropenia. ${ }^{56}$ Weekly schedules of BMS-184476 were also evaluated with BMS184476 IV on days 1,8 , and 15 without premedication, the maximum administered dose was $60 \mathrm{mg} / \mathrm{m}^{2} /$ week, and the MTD was $50 \mathrm{mg} / \mathrm{m}^{2} /$ week with neutropenia as the main toxicity and DLT. Neutropenia at the higher dose levels frequently prevented administration of the day 15 dose, and a modified schedule at MTD dosing on days 1 and 8 every 21 days was evaluated and found more feasible for Phase II studies. Antitumor activity was observed in patients with breast and NSCLC, with confirmed partial responses in $22 \%$ of patients. The recommended dose and schedule of weekly BMS- 184476 is $50 \mathrm{mg} / \mathrm{m}^{2}$ on days 1 and 8 every 21 days. $^{57}$ In a Phase II study in patients with advanced NSCLC progressing or relapsing after $\geq 1$ prior chemotherapy regimen with BMS-184476 at a dose of $60 \mathrm{mg} / \mathrm{m}^{2} \mathrm{IV}$ over $1 \mathrm{~h}$ every 21 days, $14.3 \%$ patients had PR and 58.9\% stable disease. Median PFS was 3.7 months and median OS was 10 months. BMS-184476 was well tolerated at the dose of $60 \mathrm{mg} / \mathrm{m}^{2}$ and showed evidence of antitumor activity in previously treated
NSCLC. ${ }^{58}$ A Phase IB study of BMS-184476 on days 1 and 8 with a fixed dose of doxorubicin administered on day 1 of a 21-day cycle in adults with advanced solid malignancies was performed. BMS-184476 was infused over 1 hour after bolus doxorubicin. The MTD and recommended Phase II dose of BMS-184476 was $35 \mathrm{mg} / \mathrm{m}^{2} /$ week $\left(70 \mathrm{mg} / \mathrm{m}^{2}\right.$ per cycle) in the day 1 and 8 schedule. The ORR in 17 previously untreated or minimally pretreated patients with breast cancer treated at $35 \mathrm{mg} / \mathrm{m}^{2} /$ week of BMS-184476 was 59\%. Dosing of BMS-184476 for two consecutive weeks allowed the administration of larger doses of the taxane with impressive antitumor activity in patients with untreated or minimally pretreated breast cancer. $^{59}$

\section{Toxicity}

In a Phase I study of BMS-184476 neutropenia was dose limiting but dose reduction was required in only $3.8 \%$ of cycles. Grade 4 neutropenia occurred in 19.6\% of patients, but no grade 4 thrombocytopenia or anemia was reported. Febrile neutropenia was observed in only two $(3.6 \%)$ patients and there were no life-threatening events. ${ }^{54}$ Grade 3-4 PN was reported in $9 \%$ of patients. Other nonhematological toxicities, such as nausea and vomiting, myalgia and arthralgia, diarrhea, and mucositis, were uncommon. In a Phase II study of BMS-184476 and carboplatin, neutropenia was the DLT. ${ }^{56}$ With a weekly dosage on days $1,8,15$, for an every 28-day schedule, neutropenia, and diarrhea were the main toxicities; other toxicities included vomiting, cumulative fatigue, and loss of appetite. Two patients died of neutropenia-related complications. ${ }^{57}$ The toxicities seen in the combination of BMS-184476 and doxorubicin include neutropenia (DLT), loss of appetite, asthenia, and mild, cumulative peripheral neuropathy. ${ }^{59}$

\section{Conclusion}

The development of the taxanes, paclitaxel and docetaxel, has changed the landscape of solid tumor oncology. These agents have broad-spectrum activity in solid tumor malignancies, and are currently in daily use for the treatment of advanced and early stage malignances. Continued efforts are ongoing to develop novel formulations of these agents to circumvent the need for CrEL or Tween 80 solvents, used in commercially available formulations of paclitaxel and docetaxel. Additional disadvantages of these hydrophobic cytotoxic agents are the need for prolonged infusion times (ie, paclitaxel), and the need for premedications for both paclitaxel and docetaxel (steroids and/or histamine-release blocking agents). One 
of the major common toxicities of taxanes is neurotoxicity (peripheral sensory neuropathy) which is dose limiting and cumulative. The goal of development of novel taxanes has been focused on the discovery of less neurotoxic derivatives with improved antitumor activity. Nanoparticle albuminbound paclitaxel (Abraxane ${ }^{\circledR}$ ) was FDA-approved in 2005 for treatment of anthracycline-refractory MBC. In a Phase III randomized noninferiority trial Abraxane $260 \mathrm{mg} / \mathrm{m}^{2}$ every 3 weeks was found to be superior to CrEL-paclitaxel with statistically significant improvements in RR and TTP. Caution should be used in assuming that all schedules of Abraxane are comparable in terms of activity. Recent report of a Phase III CALGB 40502/NCCTGN063H study, in chemotherapynaïve patients with $\mathrm{MBC}$ who were randomized to receive either weekly, CrEL-paclitaxel $\left(90 \mathrm{mg} / \mathrm{m}^{2}\right)$ or nanoparticlepaclitaxel $\left(150 \mathrm{mg} / \mathrm{m}^{2}\right)$ or Ixabepilone $\left(16 \mathrm{mg} / \mathrm{m}^{2}\right), 3$ weeks on 1 week off schedule; failed to show the advantage of weekly Abraxane over conventional paclitaxel; furthermore, the toxicities were enhanced in the Abraxane arm. Cabazitaxel (Jevtana ${ }^{\circledR}$ ) bears close resemblance to docetaxel, and is a semisynthetic derivative of docetaxel with impressive antitumor activity in preclinical and clinical studies in docetaxel-refractory clinical settings. Cabazitaxel was FDAapproved in 2010 for the treatment of hormone-refractory prostate cancer. In a Phase III study (TROPIC), patients with hormone- and docetaxel-refractory metastatic prostate cancer were treated with cabazitaxel or mitoxantrone; patients in the experimental arm had statistically improved median OS compared to those in the mitoxantrone arm and median PFS was doubled in the cabazitaxel group. However, the majority of men experienced grade 3 neutropenia, and a fraction experienced febrile neutropenia, and all grades PN; therefore careful patient selection and growth factor support to prevent prolonged neutropenia may be warranted, especially in highrisk populations such as the elderly.

In summary, paclitaxel and docetaxel continue to be utilized widely in the management of various malignancies despite their drawbacks, such as: poor drug solubility, toxicities and emergence of drug resistance. Ongoing drug development efforts are in place searching for new less toxic and more active analogs with new formulations to overcome these problems, but so far most of these novel compounds did not show the clinical superiority over the parent compounds. Presently, Abraxane and cabazitaxel are the recent FDA-approved taxane additions to our clinical antineoplastic drug armamentarium. Moreover, the recent successful clinical introduction of novel nontaxane microtubule-targeting chemotherapy agents such as epothilones (ixabepilone) and eribulin is liable to further restrict the development of novel taxanes and formulations.

\section{Disclosure}

The authors report no conflicts of interest in this work.

\section{References}

1. Wani MC, Taylor HL, Wall ME, Coggon P, McPhail AT. Plant antitumor agents. VI. The isolation and structure of taxol, a novel antileukemic and antitumor agent from Taxus brevifolia. J Am Chem Soc. 1971;93:2325-2327.

2. Gelderblom H, Verweij J, Nooter K, Sparreboom A. Cremophor EL: the drawbacks and advantages of vehicle selection for drug formulation. Eur J Cancer. 2001;37:1590-1598.

3. ten Tije AJ, Verweij J, Loos WJ, Sparreboom A. Pharmacological effects of formulation vehicles: implications for cancer chemotherapy. Clin Pharmacokinet. 2003;42:665-685.

4. Ibrahim NK, Desai N, Legha S, et al. Phase I and pharmacokinetic study of ABI-007, a Cremophor-free, protein-stabilized, nanoparticle formulation of paclitaxel. Clin Cancer Res. 2002;8: $1038-1044$.

5. Desai N, Trieu V, Yao R. Evidence of greater antitumor activity of cremophor-free nanoparticle albumin-bound (nab) paclitaxel (Abraxane) compared to Taxol: role of novel albumin transporter mechanism. Breast Cancer Res Treat. 2003;8:1038-1044.

6. Gradishar WJ, Tjulandin S, Davidson N, et al. Phase III trial of nanoparticle albumin-bound paclitaxel compared with polyethylated castor oil-based paclitaxel in women with breast cancer. J Clin Oncol. 2005;23:7794-7803.

7. Gradishar WJ, Krasnojon D, Cheporov S, et al. Significantly longer progression-free survival with nab-paclitaxel compared with docetaxel as first-line therapy for metastatic breast cancer. J Clin Oncol. 2009;27:3611-3619.

8. Rugo HS, Barry WT, Moreno-Aspitia A, et al. CALGB 40502/NCCTG N063H: Randomized phase III trial of weekly paclitaxel (P) compared to weekly nanoparticle albumin bound nab-paclitaxel (NP) or ixabepilone (Ix) with or without bevacizumab (B) as first-line therapy for locally recurrent or metastatic breast cancer (MBC). ASCO Meeting Abstracts. 2012;30:CRA1002.

9. Mita AC, Denis LJ, Rowinsky EK, et al. Phase I and pharmacokinetic study of XRP6258 (RPR 116258A), a novel taxane, administered as a 1-hour infusion every 3 weeks in patients with advanced solid tumors. Clin Cancer Res. 2009;15:723-730.

10. de Bono JS, Oudard S, Ozguroglu M, et al. Prednisone plus cabazitaxel or mitoxantrone for metastatic castration-resistant prostate cancer progressing after docetaxel treatment: a randomised open-label trial. Lancet. 2010;376:1147-1154.

11. Pal SK, Twardowski P, Sartor O. Critical appraisal of cabazitaxel in the management of advanced prostate cancer. Clin Interv Aging. 2010;5:395-402.

12. Shionoya M, Jimbo T, Kitagawa M, Soga T, Tohgo A. DJ-927, a novel oral taxane, overcomes P-glycoprotein-mediated multidrug resistance in vitro and in vivo. Cancer Sci. 2003;94:459-466.

13. Baas P, Szczesna A, Albert I, et al. Phase I/II study of a 3 weekly oral taxane (DJ-927) in patients with recurrent, advanced non-small cell lung cancer. J Thorac Oncol. 2008;3:745-750.

14. Saif MW, Sarantopoulos J, Patnaik A, Tolcher AW, Takimoto C, Beeram M. Tesetaxel, a new oral taxane, in combination with capecitabine: a phase I, dose-escalation study in patients with advanced solid tumors. Cancer Chemother Pharmacol. 2011;68: $1565-1573$.

15. Singer JW, Baker B, De Vries P, et al. Poly-(L)-glutamic acid-paclitaxel (CT-2103) [XYOTAX], a biodegradable polymeric drug conjugate: characterization, preclinical pharmacology, and preliminary clinical data. Adv Exp Med Biol. 2003;519:81-99. 
16. Li C, Yu DF, Newman RA, et al. Complete regression of well-established tumors using a novel water-soluble poly(L-glutamic acid)-paclitaxel conjugate. Cancer Res. 1998;58:2404-2409.

17. Li C, Price JE, Milas L, et al. Antitumor activity of poly(L-glutamic acid)-paclitaxel on syngeneic and xenografted tumors. Clin Cancer Res. 1999;5:891-897.

18. Mita M, Mita A, Sarantopoulos J, et al. Phase I study of paclitaxel poliglumex administered weekly for patients with advanced solid malignancies. Cancer Chemother Pharmacol. 2009;64:287-295.

19. O’Brien ME, Socinski MA, Popovich AY, et al. Randomized phase III trial comparing single-agent paclitaxel Poliglumex (CT-2103, PPX) with single-agent gemcitabine or vinorelbine for the treatment of PS 2 patients with chemotherapy-naive advanced non-small cell lung cancer. J Thorac Oncol. 2008;3:728-734.

20. Langer CJ, O'Byrne KJ, Socinski MA, et al. Phase III trial comparing paclitaxel poliglumex (CT-2103, PPX) in combination with carboplatin versus standard paclitaxel and carboplatin in the treatment of PS 2 patients with chemotherapy-naive advanced non-small cell lung cancer J Thorac Oncol. 2008;3:623-630.

21. Paz-Ares L, Ross H, O’Brien M, et al. Phase III trial comparing paclitaxel poliglumex vs docetaxel in the second-line treatment of non-small-cell lung cancer. Br J Cancer. 2008;98:1608-1613.

22. Sabbatini P, Sill MW, O'Malley D, Adler L, Secord AA, Gynecologic Oncology Group Study. A phase II trial of paclitaxel poliglumex in recurrent or persistent ovarian or primary peritoneal cancer (EOC): a Gynecologic Oncology Group Study. Gynecol Oncol. 2008;111:455-460.

23. US National Institutes of Health. Phase III Randomized Study of Paclitaxel Versus Polyglutamate Paclitaxel as Consolidation/Maintenance Therapy Versus No Further Anticancer Therapy Until Disease Progression in Patients With Stage III or IV Ovarian Epithelial or Primary Peritoneal Cancer or Fallopian Tube Cancer. Available from: http:// cancer.gov/clinicaltrials/GOG-0212. Accessed April 26, 2012.

24. Jeyapalan SA, Goldmann M, Donahue J, et al. A phase II study of paclitaxel poliglumex (PPX), temozolamide (TMZ), and radiation (RT) for newly diagnosed high-grade gliomas. ASCO Meeting Abstracts. 2011;29:2036.

25. US National Institutes of Health. PPX and Concurrent Radiation for Newly Diagnosed Glioblastoma Without MGMT Methylation: A Randomized Phase II Study. Available from: http://clinicaltrials gov/ct2/show/record/NCT01402063?term=glioblastoma+radiation+ brown\&recr=Open\&no_unk=Y\&rank=1. Accessed April 26, 2011.

26. Dipetrillo T, Suntharalingam M, Ng T, et al. Neoadjuvant paclitaxel poliglumex, cisplatin, and radiation for esophageal cancer: a phase 2 trial. Am J Clin Oncol. 2012;35:64-67.

27. Lin NU, Parker LM, Come SE, et al. Phase II study of CT-2103 as firstor second-line chemotherapy in patients with metastatic breast cancer: unexpected incidence of hypersensitivity reactions. Invest New Drugs. 2007;25:369-375.

28. Thurston G, McLean JW, Rizen M, et al. Cationic liposomes target angiogenic endothelial cells in tumors and chronic inflammation in mice. J Clin Invest. 1998;101:1401-1413.

29. Strieth S, Eichhorn ME, Sauer B, et al. Neovascular targeting chemotherapy: encapsulation of paclitaxel in cationic liposomes impairs functional tumor microvasculature. Int J Cancer. 2004;110:117-124.

30. Strieth S, Nussbaum CF, Eichhorn ME, et al. Tumor-selective vessel occlusions by platelets after vascular targeting chemotherapy using paclitaxel encapsulated in cationic liposomes. Int $J$ Cancer. 2008;122:452-460.

31. Strieth S, Eichhorn ME, Werner A, et al. Paclitaxel encapsulated in cationic liposomes increases tumor microvessel leakiness and improves therapeutic efficacy in combination with Cisplatin. Clin Cancer Res. 2008; 14:4603-4611.

32. Geney R, Chen J, Ojima I. Recent advances in the new generation taxane anticancer agents. Med Chem. 2005;1:125-139.

33. Bode C, Trojan L, Weiss C, et al. Paclitaxel encapsulated in cationic liposomes: a new option for neovascular targeting for the treatment of prostate cancer. Oncol Rep. 2009;22:321-326.
34. Eichhorn ME, Ischenko I, Luedemann S, et al. Vascular targeting by EndoTAG-1 enhances therapeutic efficacy of conventional chemotherapy in lung and pancreatic cancer. Int J Cancer. 2010;126:1235-1245.

35. Löhr JM, Haas SL, Bechstein WO, et al. Cationic liposomal paclitaxel plus gemcitabine or gemcitabine alone in patients with advanced pancreatic cancer: a randomized controlled phase II trial. Ann Oncol. 2012;23:1214-1222.

36. Awada A, Bondarenko I, Tarasova O, et al. Results of the first randomized phase II study of cationic liposomal paclitaxel (EndoTAG-1) targeting tumor endothelial cells in advanced triple-negative breast cancer (TNBC). Ann. Oncol. 2010;21(8s); viii5 (Abstr LBA12).

37. Bissery M, Vrignaud P, Combeau C, et al. Preclinical evaluation of XRP9881A, a new taxoid. AACR Meeting Abstracts. 2004;2004:1253a.

38. Bissery MC. Preclinical evaluation of new taxoids. Curr Pharm Des. 2001;7:1251-1257.

39. Zatloukal P, Gervais R, Vansteenkiste J, et al. Randomized multicenter phase II study of larotaxel (XRP9881) in combination with cisplatin or gemcitabine as first-line chemotherapy in nonirradiable stage IIIB or stage IV non-small cell lung cancer. J Thorac Oncol. 2008;3:894-901.

40. Dieras V, Limentani S, Romieu G, et al. Phase II multicenter study of larotaxel (XRP9881), a novel taxoid, in patients with metastatic breast cancer who previously received taxane-based therapy. Ann Oncol. 2008;19:1255-1260.

41. Kim SC, Kim DW, Shim YH, et al. In vivo evaluation of polymeric micellar paclitaxel formulation: toxicity and efficacy. J Control Release. 2001;72:191-202.

42. Zhang X, Burt HM, Mangold G, et al. Anti-tumor efficacy and biodistribution of intravenous polymeric micellar paclitaxel. Anticancer Drugs. 1997;8:696-701.

43. Zhang X, Burt HM, Von Hoff D, et al. An investigation of the antitumour activity and biodistribution of polymeric micellar paclitaxel. Cancer Chemother Pharmacol. 1997;40:81-86.

44. Kim DW, Kim SY, Kim HK, et al. Multicenter phase II trial of Genexol-PM, a novel Cremophor-free, polymeric micelle formulation of paclitaxel, with cisplatin in patients with advanced non-small-cell lung cancer. Ann Oncol. 2007;18:2009-2014.

45. Lee KS, Chung HC, Im SA, et al. Multicenter phase II trial of Genexol-PM, a Cremophor-free, polymeric micelle formulation of paclitaxel, in patients with metastatic breast cancer. Breast Cancer Res Treat. 2008;108:241-250.

46. Park SR, Oh DY, Kim DW, et al. A multi-center, late phase II clinical trial of Genexol (paclitaxel) and cisplatin for patients with advanced gastric cancer. Oncol Rep. 2004;12:1059-1064.

47. Bradley MO, Swindell CS, Anthony FH, et al. Tumor targeting by conjugation of DHA to paclitaxel. J Control Release. 2001;74:233-236.

48. Bradley MO, Webb NL, Anthony FH, et al. Tumor targeting by covalent conjugation of a natural fatty acid to paclitaxel. Clin Cancer Res. 2001;7:3229-3238.

49. Sparreboom A, Wolff AC, Verweij J, et al. Disposition of docosahexaenoic acid-paclitaxel, a novel taxane, in blood: in vitro and clinical pharmacokinetic studies. Clin Cancer Res. 2003;9:151-159.

50. Fracasso PM, Picus J, Wildi JD, et al. Phase 1 and pharmacokinetic study of weekly docosahexaenoic acid-paclitaxel, Taxoprexin, in resistant solid tumor malignancies. Cancer Chemother Pharmacol. 2009;63:451-458.

51. Homsi J, Bedikian AY, Kim KB, et al. Phase 2 open-label study of weekly docosahexaenoic acid-paclitaxel in cutaneous and mucosal metastatic melanoma patients. Melanoma Res. 2009;19:238-242.

52. Bedikian AY, DeConti RC, Conry R, et al. Phase 3 study of docosahexaenoic acid-paclitaxel versus dacarbazine in patients with metastatic malignant melanoma. Ann Oncol. 2011;22:787-793.

53. Jones RJ, Hawkins RE, Eatock MM, et al. A phase II open-label study of DHA-paclitaxel (Taxoprexin) by 2-h intravenous infusion in previously untreated patients with locally advanced or metastatic gastric or oesophageal adenocarcinoma. Cancer Chemother Pharmacol. 2008;61:435-441. 
54. Hidalgo M, Aylesworth C, Hammond LA, et al. Phase I and pharmacokinetic study of BMS-184476, a taxane with greater potency and solubility than paclitaxel. J Clin Oncol. 2001;19:2493-2503.

55. Kim JS, Amorino GP, Pyo H, Cao Q, Price JO, Choy H. The novel taxane analogs, BMS-184476 and BMS-188797, potentiate the effects of radiation therapy in vitro and in vivo against human lung cancer cells. Int J Radiat Oncol Biol Phys. 2001;51:525-534.

56. Bilenker JH, Stevenson JP, Gallagher ML, Vaughn D, Cohen MB, O'Dwyer PJ. Phase I trial of the novel taxane BMS-184476 administered in combination with carboplatin every 21 days. Br J Cancer. 2004;91:213-218.

57. Plummer R, Ghielmini M, Calvert P, et al. Phase I and pharmacokinetic study of the new taxane analog BMS-184476 given weekly in patients with advanced malignancies. Clin Cancer Res. 2002;8:2788-2797.

58. Camps C, Felip E, Sanchez JM, et al. Phase II trial of the novel taxane BMS-184476 as second-line in non-small-cell lung cancer. Ann Oncol. 2005; 16:597-601

59. Sessa C, Perotti A, Salvatorelli E, et al. Phase IB and pharmacological study of the novel taxane BMS-184476 in combination with doxorubicin. Eur J Cancer. 2004;40:563-570.

60. Villanueva C, Awada A, Campone M, et al. A multicentre doseescalating study of cabazitaxel (XRP6258) in combination with capecitabine in patients with metastatic breast cancer progressing after anthracycline and taxane treatment: a phase I/II study. Eur J Cancer. 2011;47:1037-1045.

61. Green MR, Manikhas GM, Orlov S, et al. Abraxane, a novel Cremophor-free, albumin-bound particle form of paclitaxel for the treatment of advanced non-small-cell lung cancer. Ann Oncol. 2006;17:1263-1268.

62. Rizvi NA, Riely GJ, Azzoli CG, et al. Phase I/II trial of weekly intravenous 130-nm albumin-bound paclitaxel as initial chemotherapy in patients with stage IV non-small-cell lung cancer. J Clin Oncol. 2008;26:639-643.

63. Von Hoff DD, Ramanathan RK, Borad MJ, et al. Gemcitabine plus nab-paclitaxel is an active regimen in patients with advanced pancreatic cancer: a phase I/II Trial. J Clin Oncol. 2011;29:4548-4554.

64. Hosein PJ, de Lima Lopes G, Jr, Pastorini VH, et al. A Phase II trial of nab-paclitaxel as second-line therapy in patients with advanced pancreatic cancer. Am J Clin Oncol. Epub February 2, 2012.

65. Coleman RL, Brady WE, McMeekin DS, et al. A phase II evaluation of nanoparticle, albumin-bound (nab) paclitaxel in the treatment of recurrent or persistent platinum-resistant ovarian, fallopian tube, or primary peritoneal cancer: a Gynecologic Oncology Group study. Gynecol Oncol. 2011;122:111-115.
66. Ajani JA, Sun W, Rha SY, Baker JS, Mulcahy MF. Tesetaxel, a novel oral taxane, as second-line therapy for advanced gastroesophageal cancer: Activity in a dose-ranging study. ASCO Meeting Abstracts. 2012;30:47.

67. Moore MR, Jones C, Harker G, et al. Phase II trial of DJ-927, an oral tubulin depolymerization inhibitor, in the treatment of metastatic colorectal cancer. ASCO Meeting Abstracts. 2006;24:3591.

68. Kim HJ, Kim KH, Yun J, et al. Phase II clinical trial of Genexol(R) (paclitaxel) and carboplatin for patients with advanced non-small cell lung cancer. Cancer Res Treat. 2011;43:19-23.

69. Payne M, Ellis P, Dunlop D, et al. DHA-paclitaxel (Taxoprexin) as first-line treatment in patients with stage IIIB or IV non-small cell lung cancer: report of a phase II open-label multicenter trial. JThorac Oncol. 2006;1:984-990.

70. Sun W, Stevenson JP, Gallagher ML, et al. Phase I and pharmacokinetic trial of the novel taxane BMS-184476 administered as a 1-hour intravenous infusion in combination with cisplatin every 21 days. Clin Cancer Res. 2003;9:5221-5227.

71. Cortes J, O'Shaughnessy J, Loesch D, et al. Eribulin monotherapy versus treatment of physician's choice in patients with metastatic breast cancer (EMBRACE): a phase 3 open-label randomised study. Lancet. 2011;377:914-923.

72. Thomas ES, Gomez HL, Li RK, et al. Ixabepilone plus capecitabine for metastatic breast cancer progressing after anthracycline and taxane treatment. J Clin Oncol. 2007;25:5210-5217.

73. Sparano JA, Vrdoljak E, Rixe O, et al. Randomized Phase III trial of ixabepilone plus capecitabine versus capecitabine in patients with metastatic breast cancer previously treated with an anthracycline and a taxane. J Clin Oncol. 2010;28:3256-3263.

74. Bellmunt J, Théodore C, Demkov T, et al. Phase III trial of vinflunine plus best supportive care compared with best supportive care alone after a platinum-containing regimen in patients with advanced transitional cell carcinoma of the urothelial tract. J Clin Oncol. 2009;27:4454-4461.

75. Krzakowski M, Ramlau R, Jassem J, et al. Phase III trial comparing vinflunine with docetaxel in second-line advanced non-small-cell lung cancer previously treated with platinum-containing chemotherapy. J Clin Oncol. 2010;28:2167-2173.
Drug Design, Development and Therapy

\section{Publish your work in this journal}

Drug Design, Development and Therapy is an international, peerreviewed open-access journal that spans the spectrum of drug design and development through to clinical applications. Clinical outcomes, patient safety, and programs for the development and effective, safe, and sustained use of medicines are a feature of the journal, which

\section{Dovepress}

has also been accepted for indexing on PubMed Central. The manuscript management system is completely online and includes a very quick and fair peer-review system, which is all easy to use. Visit http://www.dovepress.com/testimonials.php to read real quotes from published authors. 